\title{
Innovative Public-Private Partnership Models for Road Pricing/BRT Initiatives
}

\author{
Patrick DeCorla-Souza, Federal Highway Administration \\ William G. Barker, Urban Transportation Consultant
}

\begin{abstract}
This article presents alternative concepts for serving commuter travel demand in major metropolitan areas with a system of priced expressways integrated with Bus Rapid Transit (BRT), and presents potential new models for setting up public-private partnerships (PPP) to finance, implement, and operate the system. These new models may make possible the self-financing of new BRT services and facilitate efficient provision of multimodal transportation services. The PPP model for expressway operation uses shadow tolls to compensate private partners, while at the same time charging motorists market-based tolls to ensure free-flowing traffic conditions and to provide a fast, reliable running way for BRT. Revenues from tolls charged to users may be used to pay contractual obligations to private partners for highway operations, toll collection, and BRT services. To encourage efficient and effective provision of transit, high-occupancy vehicle (HOV, and park-and-ride/pool services, private partners may be compensated for provision of transit services and HOV promotion using shadow fee payments based on the number of commuters served.
\end{abstract}




\section{Introduction}

Transportation agencies in major, highly congested metropolitan areas in the United States (with populations in excess of 3 million, such as Washington, DC, or San Francisco) will need to fundamentally rethink the kinds of solutions that make sense. Three forces are causing a change in conventional thinking. First, a precipitous increase in congestion is accompanying growth in jobs, housing, and travel. Second, public resistance to traditional major highway projects continues due to their community and environmental impacts. Finally, many states, local governments, and regional transit authorities face funding shortfalls and do not have the financial resources to address infrastructure needs to serve growing travel demand.

Road pricing includes a group of market-based strategies that all involve collecting a variable toll for highway use, with the primary intent of managing travel demand so as to reduce or eliminate congestion on the priced roadway facility, corridor, or network. There are essentially four pricing concepts that may be employed on a freeway facility to manage traffic and provide a running way that allows Bus Rapid Transit (BRT) to operate with a high level of service:

- BRT/High-Occupancy Toll (HOT) Lanes. These are underused high-occupancy vehicle (HOV) lanes which permit non-HOVs paying an electronically charged toll, with excess revenues allocated to transit service. This model operates on the 1-15 FasTrak express lanes in San Diego. As proposed, it would be combined with BRT on the I-15 express lanes extension project, with the excess of toll revenues above operating costs supporting BRT service. Construction costs for the extension are tax-financed.

- BRT/New Priced Lanes. This includes new priced lanes on existing free roads on segments where no HOV lanes currently exist (Poole and Orski 2003). Only buses and vanpools would get free service. BRT would operate on the express lanes, but funding for BRT would not be supported from toll revenue. In most cases, revenues would not even be adequate to fully pay for costs for constructing the new lanes.

- BRT/Fast And Intertwined Regular (FAIR) Lanes. This concept (Eno Transportation Foundation 2002) would convert one or two existing free lanes to priced lanes and provide credits, established at a percentage of the toll rate, for motorists in remaining lanes. The credits would be provided electronically and could be applied to future tolls, public transportation fares, and parking charges at public transportation parking facilities. Since 
new construction is limited, surplus revenue would be available to fund BRT services. The concept may also involve adding a new priced lane while converting an existing free lane to a priced lane, for a total of two lanes in each direction. In this case, surplus revenue may not be sufficient to fund BRT services, due to new construction costs.

- BRT/FAIR Highways. This concept would convert all lanes on existing freeways to priced lanes, provide toll exemptions for HOVs and discount tolls to low-income motorists, fund BRT, and implement major traffic flow improvements on parallel arterial facilities using Intelligent Transportation Systems (DeCorla-Souza 2003a). The concept may involve adding a new lane while converting the existing freeway to a tollway. In this case, surplus revenue may not be sufficient to fund BRT services fully, due to new construction costs.

Road pricing solutions, although currently novel to members of the public and their elected and appointed governmental officials, will gain acceptance as their real-world performance becomes more widely understood. Meanwhile, Bus Rapid Transit (BRT) is receiving increasing interest as a way to enhance mobility in environments where conventional rail solutions may not be operationally feasible due to dispersed development patterns. In an era of scarce public resources and public resistance to tax increases, road pricing can bring new revenue to make road pricing/BRT projects self-financing, or nearly so. The promise of a steady stream of new revenue from tolls makes it possible to increase private sector involvement in the financing, implementation, maintenance, and operation of such projects for the mutual benefit of both public and private sectors. This article explains the synergy that can be achieved by integrating BRT into road pricing projects, proposes new models for Public-Private Partnerships (PPPs) on Road Pricing/BRT projects, and discusses the benefits to be gained from such PPP models.

\section{Integrating Road Pricing and BRT}

\section{Rationale for Market-Based Pricing of Urban Freeways}

Once freeway vehicle density (measured in vehicles per mile) exceeds a certain critical number, both vehicle speed and vehicle flow (measured in vehicles per hour) drop precipitously (Highway Research Board 1966; Transportation Research Board 2000; Chen and Varaiya 2002). Peak-period road pricing can manage travel demand to ensure that critical vehicle density is never exceeded and freeway efficiency and free flow of traffic are maintained. Essentially, a price in the form of a 
variable toll dissuades motorists from choosing to use a freeway approaching critical density and induces them to shift to carpooling and transit use. They may also shift their route or time of travel, or choose to forego the trip entirely. Solo drivers who arrive when demand is high, pay for the guaranteed congestion-free service electronically. Tolls rise when usage is high to dissuade motorists from congesting the facility. This ensures that vehicle density does not increase beyond the critical level needed to ensure that traffic flow will not break down.

Experience with the variably priced Express Lanes on SR 91 in Orange County, California, has confirmed the ability of road pricing to maximize freeway efficiency. Traffic demand on the express lanes, which became operational in December 1995, is managed using a variable toll. Initially, due to the addition of four lanes in the median, there was little congestion on the regular lanes, since total capacity had increased by 50 percent (two lanes were added per direction to the existing four lanes per direction). However, over the past few years, congestion has increased on the free lanes as demand increased due to development growth in Riverside County, from which most commuters on SR 91 come (Sullivan 2000). While the express lanes have maintained their hourly vehicle throughput in the peak hours, throughput on the free lanes in peak hours has been steadily decreasing.

By early 2004, speeds were 60 to $65 \mathrm{mph}$ on the express lanes, while congestion on the free lanes reduced average peak-hour speeds to no more than 15 to 20 $\mathrm{mph}$. Moreover, the share of vehicles carried in the peak hour on the express lanes had increased to 49 percent, based on traffic volume data provided to FHWA by the Orange County Transportation Authority for the period January 9 through March 25, 2004. Thus, the two express lanes were carrying nearly the same volume as the four free lanes in the same direction. This means that the two express lanes were carrying almost 25 percent of the vehicles per lane. This also means that the remaining four free lanes were carrying only about 12.7 percent of the vehicles per lane. The express lanes were thus carrying almost twice the number of vehicles per lane as were the free lanes. The SR 91 experience demonstrates that pricing ensures efficiency with regard to both throughput and travel speeds on freeways, maximizing return on the public's freeway investment.

As with any market-pricing mechanism, road pricing helps allocate limited supply of road space. With user charges assessed at the point of use, greater efficiency results through improved response to market forces. Under conventional taxation, while users pay for the facilities they use, price signals are not available to balance demand and supply, leading to queuing and congestion. Congestion costs 
imposed on other motorists by each new motorist on the highway (marginal costs) increase geometrically as traffic volume increases. Pricing is especially effective when marginal costs increase with scale. Road tolls set at marginal cost can significantly decrease congestion costs by dissuading motorists from using highway facilities when the value they derive from highway use (revealed by their willingness to pay marginal cost charges) is less than the marginal costs they impose.

Incremental costs for supply of new road space are also significant. Recent construction cost data suggest that average costs for providing additional peak-period capacity on urban freeways amount to as much $\$ 10$ million per lane mile (Federal Highway Administration 2000a), which equates to about 32 cents per mile driven on the added lane in peak periods (DeCorla-Souza 2004a). A lower bound of the range of estimates for external costs for air pollution, noise, and crashes is 6 cents per mile driven, based on the lower bound estimate of the nationwide estimates of these costs and vehicle miles of travel (Federal Highway Administration 2000b). Freeway operation and maintenance costs amount to about 1 cent per mile driven. Combined incremental costs for highway supply and externalities associated with peak-period highway use thus amount to about 39 cents per mile. On the other hand, motorists pay fuel taxes amounting to only 2 cents per mile driven. This is calculated based on combined federal and state fuel taxes averaging 40 cents per gallon and fuel efficiency of 20 miles per gallon. Other vehicle charges (e.g., registration fees) amount to less than 1 cent per mile driven (Federal Highway Administration 2003). Highway user charges for peak-period freeway use thus amount to less than 3 cents per mile driven. The difference between motorist fees and incremental costs for roadway supply and externalities associated with peak use of road space is about 36 cents per mile driven. This suggests that an average peak-period toll rate of 36 cents per mile may be justified on urban freeways.

\section{Rationale for BRT in Major Travel Corridors}

In the United States, interest in BRT is increasing as an alternative to rail transit due to competitive cost and greater flexibility in serving more dispersed origins and destinations in suburban environments. A key feature of BRT is that it provides frequent, fast, reliable, and identifiable service on a free-flowing lane.

As Lewis and Williams (1999) and Mogridge (1997) have observed, an improvement in high-capacity transit service reduces travel times on all modes in a congested corridor. This phenomenon is known as Mogridge-Lewis convergence. It can be assumed that BRT service on a free-flowing HOT lane would have an impact on travel times on other modes in a congested corridor as well. A free-flow- 
ing transit system would attract more riders from the adjacent congested highway as the frequency of the transit service (and therefore the travel time advantage) increases. Travel time equilibrium is reached among the modes, with transit travelers accepting a few extra minutes of travel time probably in exchange for the reduced travel costs associated with transit use. While the capacity of a transit system has some limits, in this situation it can be ignored as a constraint, since additional BRT vehicles can easily be accommodated on the priced lanes.

Priced lanes implemented without BRT attract motorists from congested lanes, improving travel times in the corridor for all modes until the maximum throughput of the priced lanes is reached and the magnitude of the tolls discourages further lane switching. If a BRT line was added to the priced lanes in the same corridor, it would further add person-carrying capacity and permit travel times to continue to improve for even more commuters. An important consideration will be to balance the BRT system's need for service frequency with a conventional toll road franchise's objective of maximizing revenue by maximizing the number of toll-paying vehicles and limiting free service and competition from new personcarrying capacity.

While the BRT/HOT concept is believed to be workable in radial corridors (Barker and Polzin 2004), can it be used in a suburb-to-suburb travel context? Certain factors work against transit use for suburb-to-suburb travel and may keep ridership too low to make high frequency service feasible. These factors include (Newsom, Wegmann, and Chatterjee 1992; Cervero 1993):

- Plenty of free parking at suburban worksites

- Low density development with a dispersed many-to-many trip end distribution

- Lack of a central business district or other activity concentrations

- Urban design that is auto-oriented and unfriendly to pedestrian and transit use (e.g., large building set-backs and wide, high-volume streets)

- Separated land uses with relatively long distances between them

- Higher incomes and auto ownership levels

- An automobile mindset (e.g., one wouldn't move to the suburbs without planning to use an automobile for travel)

In particular, attempts at planning suburban activity centers have resulted in varying degrees of success in creating a transit- and pedestrian-friendly environment 
(Filion, McSpurren, and Huether 2000). It is not sufficient to simply have a concentration of high density, mixed-use activity. However, these challenges to transit have not kept very large metropolitan areas from proposing suburb-to-suburb rail transit systems (Gurwitt 2003). BRT could provide similar levels of service while more efficiently addressing access to the line-haul portion of the system. Modeling studies suggest that, when combined with peak-period road pricing strategies, the significant transit travel-time reductions achieved by BRT in highly congested travel corridors may contribute to significant shifts in travel demand from auto modes to BRT (DeCorla-Souza 2003b; DeCorla-Souza 2004b). Even in suburb-tosuburb travel corridors of major metro areas (with major activity centers located along the BRT route), sufficient transit travel demand may be generated to make high-frequency BRT service feasible during the peak-travel periods when tolls are in effect.

\section{Synergy with Integration of Road Pricing and BRT}

Road pricing provides two key benefits for BRT:

- By managing traffic demand on a single or multiple freeway lanes to ensure free flow of traffic, road pricing will be able to provide a fixed guideway-like running way for operation of BRT.

- Road pricing generates revenues, which may be used for financing the operation and maintenance of the BRT system as well as to support bonds for capital improvements (stations, park-and-ride facilities, and rolling stock).

$B R T$, likewise, impacts the feasibility of road pricing in two key ways:

- Technical Feasibility. The effectiveness of road pricing strategies increases when motorists have the option of choosing a viable alternative mode. With new BRT service on priced highways, auto travel demand could be reduced without resorting to exorbitant and punitive toll rates to ensure that demand does not exceed levels needed to ensure free flow. Commuters benefit from lower toll rates for those motorists who continue to drive and better transit service for those who choose to use it. The addition of the BRT system should prevent the travel corridor from reaching its person-carrying capacity based on use of the auto mode alone.

- Political Feasibility. By keeping toll rates affordable, and by providing a viable alternative for those who may not be willing to pay the toll, BRT increases the public acceptability of road pricing and ensures that equity is preserved for 
low-income commuters. Addressing public acceptance and equity concerns is key to political feasibility of road pricing strategies.

\section{Implementing Integrated Road Pricing/BRT Projects with PPPs Benefits of PPPs}

Procuring transportation facilities and services through PPPs has many advantages over the traditional publicly financed approach (Kopp 1997):

- Projects are generally planned and constructed more quickly.

- Capital demands on the public treasury are reduced.

- Innovation in technology is encouraged.

- Private sector organizations may enjoy significant economies of scale, scope, and experience in the production and management of an international portfolio of projects. Risks may be spread across a diversified spectrum of projects.

- Efficiencies result from exempting private developers from traditional government procurement rules.

- Income is generated for local, state, and national governments from property and income taxes paid by private business.

The federal government, as well as several state and local governments, have shown increasing interest in private sector involvement in the provision of transportation infrastructure and services. Given the innovative aspects of both road pricing as well as BRT, advances in innovation as well as efficiency may be encouraged through greater involvement of the private sector. The following section discusses the issues and suggests a model for PPP agreements that could reduce costs by managing the risks to both public and private sectors.

\section{Issues with Regard to Road Pricing}

Pursuit of PPP arrangements for road pricing projects raises some special issues. Efficient freeway operation may occasionally require relatively high charges to keep traffic free flowing during rush hours when travel demand is very high. This may be perceived by the public as price gouging, particularly if revenues and resulting profits go to the private sector. For example, Sullivan (2000) reports that approval of private companies operating a toll road for profit is far lower than approval of tolling itself in the SR 91 corridor in Orange County, California. 
In a PPP arrangement, providing for financing of highway investment and operations, it is important to ensure that the public does not perceive that the private sector partner is attempting to maximize profits through excessive peak charges, while the public agency does nothing to relieve congestion on free facilities. This occurred in Orange County, where a noncompete clause in the PPP agreement for the express lanes prevented the public agency from making improvements on the free lanes of SR 91 (Sullivan 2000). Simply eliminating or limiting noncompete provisions is not a solution, because the private sector would be unwilling to invest in highway projects without adequate protection against future competition.

\section{A New PPP Model for Road Pricing Implementation and Operation}

To address the issues discussed above, a new model is suggested. It separates the system operator from the revenue beneficiary. The PPP agreement would employ shadow tolls to compensate the private partner. Shadow tolls are usage payments made by a third party. The public agency would pay the private partner a shadow toll based only on the number of vehicles served at free-flow speeds during rush hours, when proactive management of traffic flow with variable tolls is needed. In addition, road users would be charged tolls directly. The private partner would set the user-paid toll rates to manage demand and ensure that traffic is free-flowing (as the express lanes on SR 91). However, all toll revenues would go to the public sector. User-paid toll rates would rise as high as they need to be in order to manage demand effectively, but the private partner would not profit from the resulting increase in user-paid toll revenue relative to shadow toll revenue.

Potential private partners would compete to build and operate the road project on the basis of the quality of their proposals and the shadow toll rates that they are willing to accept as compensation for their infrastructure investments, freeway operation, and toll collection services. Agreements with the private partner will need to include customer service standards (e.g., highway signage, billing, customer service centers), since the private partner could attempt to gain additional profits by reducing quality of service to the public.

If the shadow toll rate negotiated with the private partner is less than the user-paid toll rate, there could be public pressure to reduce user-paid tolls. In this case, it may be relatively simple to demonstrate to the public the advantages of the higher user-paid tolls. For a few days, actual toll rates could be set to match shadow toll rates. The public would then see the resulting effects on overall congestion as well as level of service on the toll lanes. Such an experiment was recently conducted with regard to freeway ramp metering in the Twin Cities metropolitan area in 
Minnesota to convince the public of the benefits of ramp metering. There are also many examples of toll facilities employing flat tolls that suffer congestion in peak periods because tolls are not high enough to manage demand in peak periods.

Nevertheless, to ensure the trust of the public, it will still be important to assure them that excess revenues from higher tolls will be used for the benefit of those paying the tolls. Excess revenues could be dedicated to pay for additional transportation services in the corridor. The public is more likely to accept this strategy over the single-service approach used in the initial PPP arrangement for the express lanes on SR 91 (Deakin 1996). This will also assure the public that government will not waste the money (see Figure 4-9 in Sullivan 2000). Sullivan reports that in the SR 91 corridor, more than half the opposition to tolling existing lanes seems related to opposition to government receiving more funds.

\section{Benefits of the New Model for Road Pricing}

The new PPP approach for road pricing will reduce public and private risks (and therefore financing costs), deliver services more efficiently and effectively, and maximize mobility. These benefits are discussed below.

\section{Public and Private Risk}

Public risk will be greatly reduced with regard to uncertainty of costs for the innovative technology and operations approaches that will be needed. The public sector would know in advance its maximum cost liability, calculated as the maximum possible vehicle throughput per hour, times the number of peak hours of pricing operations, times the shadow toll per vehicle negotiated with the private partner. The public sector could prepare a financial plan that allocates future receipts from its normal federal, state, and local funding sources to pay for contractual obligations to the private partner. Thus, risks associated with reliance on difficult-to-predict revenues would be minimized.

Private sector risk would also be reduced, reducing financing costs. The private partner would be assured of an almost guaranteed stream of revenue based on the negotiated shadow roll rate. This would reduce risk-related costs for financing in the capital markets. For example, risks to bond holders would be reduced, lowering the interest rate demanded. Risk with regard to revenue receipts from user-paid tolls will be borne by the public sector. Therefore, the private partner would not need to be too concerned about the accuracy of 
travel growth forecasts, since priced lanes can be guaranteed to be filled to critical density threshold levels simply by lowering the user-paid toll rate.

Also, the private partner would not need to be too concerned about potential effects of competition from possible future improvements that may be made by the public agency on parallel highway facilities. Neither would there be concerns about competition resulting from efforts to improve HOV or transit services. Under normal toll road franchises, these would be of concern because they reduce demand for vehicle use on the tolled facility and the market-clearing price that motorists could be charged. Since the private partner would receive the same monetary reimbursement (i.e., shadow toll) per vehicle, no matter what type of improvements may be made to competing modes and routes, there would be no need in the PPP agreement for a noncompete clause such as the one that led to the termination of the PPP for the express lanes on SR 91 in Orange County, California. If the public partner chooses to improve alternative routes or modes, it absorbs all the risks to user-paid toll revenues.

Service Delivery and Quality

Services would be more efficiently delivered. To maximize its profit, the private partner would strive to keep costs down through innovation, and would use efficient procurement and management practices.

Services would be more effective. The private partner would have an incentive to maximize peak-period vehicle throughput, while ensuring that all traffic moves at free-flow speeds. Since the private partner would only be paid for vehicles that are provided with free-flowing premium service, there would be an incentive to ensure that traffic flow does not break down. Should traffic flow disruptions occur (due to accidents, incidents, or repairs), the private partner would be at risk of losing shadow toll revenue and would be likely to clear them as soon as possible. To reduce traffic flow disruptions, the private partner would also be likely to produce innovative solutions to reduce the risk of accidents and the frequency of maintenance operations during rush hours. As on the SR 91 express lanes, a private operator could be required to refund tolls charged to toll-paying motorists who did not get congestion-free service. 
Mobility

Mobility benefits would be maximized, rather than revenue. There would be no incentive for a private operator to keep the charges per vehicle high, simply in order to maximize revenue. Higher charges than needed to manage traffic result in mobility losses, as motorists are unnecessarily dissuaded from traveling or are unnecessarily shifted to alternative routes. This is the case with a typical toll road franchise. Tolls are charged during off-peak periods to maximize revenue, even though plenty of capacity may be available on the facility. With the new PPP model, charges would only be as high as needed to ensure efficient free-flowing freeway operation with maximum vehicle throughput. Also, tolls would be unnecessary in the off-peak periods if spare capacity were available, and would not be charged.

\section{A New PPP Model for Transit or HOV Services}

A PPP arrangement similar to the concept described above may be used to provide improved transit or HOV services. The private partner would be compensated by the public partner with a base service fee payment plus a usage payment (similar to the shadow toll) for each transit or HOV trip served above a base usage level. This usage payment per trip would make up for the difference between fares and the marginal cost per trip for providing service above the base usage level. With shadow usage payments, the private partner stands to increase its revenues (and potentially, profits) by increasing the use of transit or HOVs. This would increase its incentive to promote transit and HOV use and to maximize their use, resulting in public benefits from reduced roadway usage during peak times.

Shadow usage payments are justified since a significant share of benefits from shifts to transit and HOV modes accrue to the general public and not directly to the user. While transit and HOV commuters may save money over driving solo, they may experience longer travel times, including more onerous walk and wait times. They are constrained as to the time of travel and may not be able to do things they would be free to do if they were driving solo (e.g., eat, drink, smoke, talk for long periods on their cell phones, play loud music of their choice on their car stereo systems). On the other hand, nonusers benefit from lower pollutant emissions, less dependence on foreign oil, less congestion, higher development densities, and other social benefits that accrue from reduced traffic levels.

HOV shadow fee payments and transit shadow usage payments may not be costefficient if they exceed the estimated values of external benefits (e.g., the reduction 
in external costs resulting from solo driver trips eliminated). Therefore, it is important for a public agency to have the capability to estimate the value of changes in external costs resulting from mode shifts. External benefits may be estimated using the Transportation Research Board's Guidebook to Estimate and Present Benefits and Disbenefits of Public Transit (ECONorthwest and Parsons Brinckerhoff Quade \& Douglas, Inc. 2003). If the bid price from a private partner for shadow fee payments per trip is higher than the marginal external benefit, the PPP contract may not be economically justified.

As in the case of road pricing PPP agreements, private partners could finance transit or HOV investments by going to the capital markets and availing of credit support from the federal government under the Transportation Infrastructure Finance and Innovation Act of 1998 (TIFIA), backed by the projected revenue stream from fares and shadow usage payments. The mix and intensity of transportation options in a corridor may warrant a special taxing district established by the public partner to generate additional funds for shadow usage payments. In addition, the public partner might reduce parking requirements for new or expanded buildings served by BRT with a contribution to the corridor transportation program, in lieu of the expense of expanded parking. Value-capture techniques may be applied, but, in general, the auto-oriented character of most development in freeway corridors is not expected to generate many value-capture opportunities for transit, although it could for highway elements.

Application of the Model for Transit

The PPP arrangement for transit would make over-the-road bus service commercially viable for transit travel within the corridor. Minimum transit performance and safety service standards (e.g., service frequency, passenger load factors, vehicle condition) could be set by the public partner to ensure quality of service. Base service payments to be made to the private transit operator could be determined on the basis of the cost of minimum required service level set by the public agency less expected fare revenue, with adjustments allowed for fuel prices. Shadow usage payments for riders above the specified base level of transit ridership would be based on an automatic accounting of the number of riders carried. Accounting would be facilitated by requiring use of electronic fare payment (using a smart card) for anyone wanting to get the subsidized fare. 
Application of the Model for HOV Services

Carpools and vanpools are often perceived as competitors to transit, since the modes have many similar characteristics. A private partner operating transit services would, therefore, be concerned about the risk of competition from any efforts to increase HOV use. To address this issue, the private partner operating transit services would also be under contract to run the HOV promotion program, and would be compensated through a base service fee payment plus a shadow fee per HOV trip above a base HOV usage level (the level of HOV use observed immediately after implementation of the road pricing program).

Protection would be provided for the public partner in the event that unexpected shifts to carpooling occur due to external factors such as a fuel shortage or significant fuel price increase. This could be done by limiting the number of new HOV trips for which it would pay a shadow fee, or by using a fee schedule that decreases as HOV volume increases. Keeping track of the number of HOVs would be relatively easy because each HOV would be identified electronically (such as passing through special lanes upon entry into the priced facilities) in order to receive a toll exemption (DeCorla-Souza 2003a).

Under a conventional toll road franchise, the private operator responsible for the tolled lanes would be concerned about reduced revenues from carpools, if carpools are required to be provided free service. However, this will not be a problem with the PPP model proposed in this article, because the private operator of the priced lanes will be compensated by a shadow toll for every vehicle, whether it is a single-occupant vehicle, HOV, or a transit vehicle.

\section{Benefits of the New PPP Model for Transit or HOV Services}

The new PPP approach for transit and HOV service delivery suggested above could be more economically efficient than a conventional service delivery approach, and could encourage service delivery innovation, as discussed below.

\section{Economic Efficiency}

Economic efficiency and social benefits could be maximized. The private partner would have an incentive to promote transit use up to the point where the total revenue from the transit fare payment (a proxy for the transit rider's benefit) and the shadow usage payment per trip (a proxy for the external ben- 
efit) would be just equal to its marginal costs for providing service. Similarly, the private partner would have an incentive to promote HOV use up to the point where the shadow fee payment per HOV trip (a proxy for the external benefit) would be just equal to its marginal costs for promoting and providing HOV service. This would maximize economic efficiency and net social benefits.

Shadow fee payment schedules could be designed to cost efficiently maximize the person throughput of the transportation corridor. If the shadow fee payment rates were set carefully, the private partner would be in a position to seek the most socially cost-efficient mode (transit or HOV) with which to serve the commuter. The operator would have an incentive to maximize transit ridership and HOV use in order to maximize its total revenues. Base transit service frequency requirements will ensure that the shadow fee per HOV does not provide an incentive to the private partner to increase HOV use at the cost of transit ridership to such an extent that it results in a significant reduction in transit service frequency, thus compromising the quality of BRT service.

Service Delivery and Innovation

The incentive to maximize transit ridership, if successful, could lead to more riders and, therefore, more frequent service. All transit riders would gain, because any increase in service frequency will reduce waiting time.

The private partner would also have an incentive to provide additional premium services for those willing to pay a higher fare (e.g., door-to-door limousine services similar to airport shuttles, or vanpool services), provided that the private partner would still be eligible to get the agreed-upon shadow usage payment per rider from the public agency. Private operators would have an incentive to work with Transportation Management Associations to encourage employees to take transit or carpool. They might innovate with such concepts as fare agreements with employers and building owners, provision of additional services and conveniences such as station cars and park-and-ride/ pool lots, and TravelSmart marketing programs (Western Australian Department of Transport 2000) that ask people to make voluntary changes in their travel choices and encourage them to use other ways of traveling, rather than driving alone in a car. 


\section{Potential Demonstration Projects}

Public trust, understanding and acceptance of the innovative transportation, road pricing, and PPP concepts discussed above may be facilitated with a pilot project. This section discusses three potential candidate pilot projects.

The criteria for selecting a pilot project include those characteristics that will both support roadway pricing and sufficient transit use. For roadway pricing, high volume, congested travel for much of the day is a desirable existing condition. For BRT, as guidance from suburban mobility research suggests (Urbitran Associates, Inc. et al. 1999), criteria may include:

- Real employer support

- Participatory planning and local support

- Congestion and parking fees that make automobile travel less attractive

- High density destinations

- Reasonably populated residential market sheds

- Supportive regional planning

- Transit-dependent populations

- Special rolling stock

Based on the above criteria, three potential pilot projects are identified in the Washington, DC metropolitan area.

\section{Dulles Toll Road}

Variable tolls to eliminate congestion may be piloted most easily in an existing congested travel corridor with a tolled freeway. Such an opportunity exists in the Dulles Toll Road corridor in Northern Virginia. The Dulles Toll Road Authority could enter into an arrangement with a private partner to implement dynamic peak-period tolls for single-occupant vehicles (SOVs) to ensure free-flowing traffic conditions. Surplus revenues could be used to pay private partners or public agencies to provide new or enhanced transit and HOV services in the corridor, including toll discounts for HOVs.

Compensation for dynamic pricing operations would be provided in the form of shadow toll payments for each vehicle provided congestion-free service in the peak period. Compensation for transit and HOV services would be in the form of usage payments based on the number of new transit riders and new HOV commuters. Since availability of parking spaces at park-and-ride/pool facilities can be 
a limiting factor for these services, the private partner would have an incentive to innovate with new parking arrangements, feeder services, new transit centers, and station cars to maximize transit and HOV use.

\section{Interstate 66}

Integrated road pricing/transit strategies may also be demonstrated on I-66 inside the Capital Beltway in Northern Virginia. The facility is currently congested in peak hours, despite being restricted to $\mathrm{HOV} 2+$ vehicles. $\mathrm{HOV}$ occupancy requirements could be raised back to the original HOV3 + requirement, and HOV2 and SOV use could be permitted with payment of a peak toll that varies to ensure free flow of traffic.

Revenues would go first to pay the private partner for operation of the existing facility during peak periods using the shadow toll concept. Surplus revenues would be dedicated to improve or further subsidize transit service in the corridor, establish new parking arrangements, create new transit centers, set up station cars, pay for feeder services, provide additional parking for transit or HOV riders, and make highway safety improvements.

Since availability of parking is currently the limiting factor at Metro transit stations, private provision of parking facilities may be encouraged through a program that offers private parking providers a subsidy payment for each transit rider who is provided with parking near a Metro station or bus stop at a specified rate below market price. Transit riders would be identified through use of Metro's electronic SmarTrip card. They would need to use SmarTrip to pay for parking as well as transit fares to the park-and-ride or transit station where their cars are parked. This would reveal whether the parker had indeed transferred from a transit vehicle.

\section{Capital Beltway}

Applying the concept might be much more difficult in a heavily traveled suburb-to-suburb travel corridor such as the Capital Beltway (1-95/1-475) corridor in Northern Virginia. No HOV lanes currently exist on the Beltway.

A study by the Virginia Department of Transportation and the Federal Highway Administration (2002) and a private sector proposal for new HOT lanes for the Capital Beltway (Fluor Daniel 2003) suggest that costs for constructing new lanes cannot be financed solely from toll revenues, and HOT lane operating costs and any new transit services would need to be supported using tax dollars. Thus, to ensure self-financing capability, it would be necessary to convert one or two existing lanes to BRT/HOT lanes or BRT/FAIR lanes to generate sufficient revenue to 
support implementation of BRT. However, significant public outreach and education with regard to costs, revenues, and benefits of alternative concepts will need to be conducted before such a concept can be entertained in the political arena.

\section{Summary}

This article has presented alternative concepts for serving commuter travel demand in major metropolitan areas with a system of priced expressways integrated with Bus Rapid Transit. The article has also presented potential new models for setting up public-private partnerships for the delivery of such a system. The models employ outcome-based contracting systems and incorporate financial incentives to maximize public mobility goals, with clear performance standards to ensure service quality. The models address public concerns relating to private sector monopoly power, as well as private sector concerns about competition from alternative modes and highway routes. At the same time, the models facilitate efficient provision of new multimodal transportation services and maximize mobility and freeway efficiency. A pilot demonstration of these models would help considerably in gaining public understanding, trust, and acceptance of these innovative concepts.

\section{Acknowledgments}

The authors would like to acknowledge helpful comments on an earlier version of this paper from anonymous reviewers of the Journal of Public Transportation, as well as several colleagues at the Federal Highway Administration (FHWA), the Federal Transit Administration (FTA), and the U.S. Department of Transportation's (USDOT) Office of the Secretary. However, the authors alone are responsible for any errors or omissions, and the views expressed are those of the authors and not necessarily those of the USDOT, FTA, or the FHWA. 


\section{References}

Barker, William G., and Steven Polzin. 2004. Synergies between Bus Rapid Transit and High Occupancy Toll lanes: A simulation of Bus Rapid Transit in a congested corridor with roadway value pricing. Presented at the annual meeting of the Transportation Research Board.

Cervero, R. 1993. Surviving in the suburbs: Transit's untapped frontier. Access 2: 29-34.

Chen, Chao, and Pravin Varaiya. 2002. The freeway-congestion paradox. Access. 20, Spring. Downloadable from website: http://www.uctc.net/access/access20.pdf.

Deakin, Elizabeth. 1996. Transportation pricing strategies for California: An assessment of congestion, emission, energy, and equity impacts. ARB Contract No. 92-316. University of California, Berkeley.

DeCorla-Souza, Patrick. 2003a. Clearing existing freeway bottlenecks with FAIR networks: Issues and impacts. Presented at the annual meeting of the TRB in January 2004. Paper No. 04-3993. Available on Meeting CD-ROM. Downloadable from website: $h t t p: / / k n o w l e d g e . f h w a . d o t . g o v / c o p s / h c x$. nsf/9ba8442069238e44852568fe00708985/a5a934a66798f6aa85256de00000a7 13?OpenDocument.

DeCorla-Souza, Patrick. 2003b. Evaluation of toll options with quick-response analysis tools. Transportation Research Record 1839. Paper No.03-2946. Transportation Research Board.

DeCorla-Souza, Patrick. 2004a. Implementing priced freeway networks in metropolitan areas: Benefits and prospects. ITE Journal. July 2004: 73-78.

DeCorla-Souza, Patrick. 2004b. Road pricing: The trade-off between transportation performance and financial feasibility. Prepared for presentation at the annual meeting of the Transportation Research Board in January 2005. Paper No. 05-1429. Downloadable from website: http://knowledge.fhwa.dot.gov/cops/hcx.nsf/9ba8442069238e44852568fe00708985/ 84a8bc9ccc22f7c385256f010066776b?OpenDocument.

Eno Transportation Foundation. 2002. The role of Fast And Intertwined Regular (FAIR) lanes in the New York metropolitan region. Washington, DC. Available on the web at: http://www.fhwa.dot.gov/policy/otps/fairlanes.htm. 
ECONorthwest and Parsons Brinckerhoff Quade \& Douglas, Inc. 2003. TCRP Report 78: Estimating the benefits and costs of public transit projects: A guidebook for practitioners. Washington DC: Transportation Research Board. Available on the web at: http://gulliver.trb.org/publications/tcrp/tcrp78/index.htm.

Federal Highway Administration. 2000a. Highway economic requirements system. Technical Report IV.

Federal Highway Administration. 2000b. Addendum to the 1997 Federal Highway Cost Allocation Study. Washington, DC. FHWA-PL-00-021.

Federal Highway Administration. 2003. Highway statistics 2002. Washington, DC. FHWA-PL-03-010.

Filion, Pierre, Kathleen McSpurren, and Nancy Huether. 2000. Synergy and movement within suburban mixed-use center: The Toronto experience. Journal of Urban Affairs 22 (4): 419-438.

Fluor Daniel. 2003. Capital Beltway HOT lane: Detailed proposal. Available on the web at: http://www.virginiadot.org/projects/ppta-defaultHOTLANESCapitalBeltway-proposals.asp.

Gurwitt, Rob. 2003. Connecting the suburban dots. Governing Magazine. Congressional Quarterly. October.

Highway Research Board. 1965. Highway capacity manual, special report 87. Washington, DC.

Kopp, John Christopher. 1997. Private capital for public works: Designing the nextgeneration franchise for public-private partnerships in transportation infrastructure. Master's thesis submitted to the Department of Civil Engineering, Northwestern University. Available at: http://www.iti.northwestern.edu/clear/ infr/kopp/.

Lewis, David, and Fred L. Williams. 1999. Policy and planning as public choice: Mass transit in the United States. Vermont: Ashgate Publishing Company.

Mogridge, Martin J. H. 1997. The self-defeating nature of urban road capacity policy: A review of theories, disputes and available evidence. Transport Policy $4(1): 5-23$.

Newsom, T. J., F. J. Wegmann, and A. Chatterjee. 1992 Suburban mobility: A challenge for public transportation. Transportation Center, The University of Tennessee, Knoxville. 
Poole, Robert, and C. Kenneth Orski. 2003. HOT networks: A new plan for congestion relief and better transit. Reason Public Policy Institute. Policy Study No. 305.

Sullivan, Edward. 2000. Continuation study to evaluate the impacts of the SR 91 value-priced express lanes. Final Report. Cal Poly State University, San Luis Obispo. Downloadable from website: $h t t p: / / c e e n v e . c a l p o l y . e d u / s u l l i v a n / s r 91 /$.

Transportation Research Board. 2000. Highway capacity manual. Washington, DC.

Urbitran Associates, Inc., Multisystems, Inc., SG Associates, Inc., and Robert Cervero. 1999. Guidelines for enhancing suburban mobility using public transportation. Transit Cooperative Research Program Report 55. Washington, DC: National Academy Press.

Virginia Department of Transportation and the Federal Highway Administration. 2002. Capital Beltway study. Draft Environmental Impact Statement. Volume 1.

Western Australian Department of Transport 2000. TravelSmart. West Perth: The Shorter Group. Downloadable from website: http://www.dpi.wa.gov.au/travelsmart/pdfs/highlights.pdf.

\section{About the Authors}

Patrick DeCorla-Souza (patrick.decorla-souza@fhwa.dot.gov) is team leader for Highway Pricing and System Analysis in the Office of Transportation Policy Studies at the Federal Highway Administration (FHWA) in Washington, DC. He manages FHWA's Value Pricing Pilot Program. In this capacity, he works with public and private sector partners in 15 states to implement innovative road pricing strategies. He has published extensively on topics relating to road pricing, air quality, travel demand modeling, land-use strategies, benefit-cost analysis, and cross-modal evaluation. Mr. DeCorla-Souza chairs the Transportation Research Board's Joint Subcommittee on Road Pricing.

WiLlIAM G. BARKER (bill.barker@grandecom.net) is an urban transportation consultant, researcher, and planner with more than 35 years of professional experience about equally divided between the public and private sectors. Besides VIA Metropolitan Transit in San Antonio, he has worked for the U.S. Department of Transportation and the North Central Texas Council of Governments (the Metro- 
Journal of Public Transportation, Vol. 8, No. 1, 2005

politan Planning Organization in the Dallas-Fort Worth area). As a consultant, he has helped public and private clients in seven states, Canada, and Mexico. He is a member of the Transportation Research Board's Bus Systems Committee and its BRT Subcommittee. 